\title{
BANDIDAJE Y ADAPTACIÓN SOCIAL: ROBIN HOOD AL FINAL DE LA EDAD MEDIA
}

\author{
Ma BEATRIZ HERNÁNDEZ PÉREZ \\ Universidad de La Laguna
}

\section{RESUMEN}

Como todas las figuras míticas, la de Robin Hood se resiste a ser encuadrada en un momento histórico determinado. Así, frente a quienes intentan descubrir un Robin de carne y hueso, seguimos constatando mediante la literatura y el cine que el personaje encarna el sueño de los oprimidos de cualquier signo. En este estudio no pretendemos aportar datos que confirmen su identificación histórica sino presentar al forajido como encarnación, desde nuestro punto de vista, de la dinámica social de la baja edad media inglesa, representada asimismo en la propia adaptabilidad de la balada.

\begin{abstract}
Like most mythical characters, Robin Hood evades the possibility of being constrained by a particular historical moment. Facing those scholars who try to determine a real flesh and blood figure, literature and the film industry persist in presenting him as the incarnation of freedom wishes for all types of audiences, and thus, as an adapted type to the diversity of expectations arising at each moment. This paper does not try to provide with new evidence that confirms his historical existence but rather to search for the historical conditions that allowed him to become, from our point of view, the incarnation of the very social dynamics of late medieval England, which are equally represented by the adaptability of the ballad.
\end{abstract}

Mucho antes de transformarse en uno de los héroes nacionales ingleses, Robin Hood era ya era el héroe local, casi familiar de cada condado y aldea del país. ${ }^{1}$ Su popularidad, de

\footnotetext{
1 Si a la identidad real nos referimos, podemos remitirnos a la inmensa cantidad de Robin Hoods registrados en diversos archivos desde el siglo XIII, casi siempre relacionados con actos criminales. Entre los historiadores que han perseguido incansablemente al personaje destaca la labor de más de treinta años de Joseph Hunter, archivero de la Public Record Office (desde 1852) que siguiendo los datos de la Geste, pensó que el rey referido en ella sería Eduardo II en su viaje de 1323 a Yorkshire y Lancashire. Descubrió un Robin Hood al que se despide de su puesto de portero de la cámara real en 1324, y que puede o no ser el Robert Hood casado con una tal Matilda y residente en Wakefield en 1316-17. Éste había apoyado a
} 
la que da cuenta la ingente cantidad de estudios críticos que su figura ha inspirado, ${ }^{2}$ responde a que está, de hecho, compuesto de toda una serie de superposiciones míticas e históricas, y a que incorpora a su identidad cambiante una sucesión de discursos; discursos sobre la disidencia y la adaptación a las instituciones y los poderes establecidos, que trataremos de esbozar. Este motivo de la disidencia parece consustancial al propio personaje. En Piers Plowman, Pereza confiesa que conoce las baladas del forajido mejor que las oraciones. ${ }^{3}$ Hemos de preguntarnos qué hay de reprobable en este personaje para que aparezca en el contexto de la confesión. Quizás la respuesta esté simplemente en el efecto que producía: alejar a los feligreses de los buenos hábitos de la Iglesia. ${ }^{4}$ El propio John Paston (Davis, 1971: 275) informa en su correspondencia de 1473 que su sirviente ha partido desde Norfolk hasta Barnsdale para participar en una función de Robin Hood.

Si esa disidencia era lo que hacía al personaje popular, nos planteamos si ese supuesto germen subversivo del personaje sería asumido por la estructura social de la tardía Edad Media inglesa como forma de integrar y acallar otras posibles discrepancias. Intentaremos, para decidir sobre este punto, hacer un recorrido por las supuestas identidades que se han dado al héroe, teniendo en cuenta, además, los posibles auditorios a los que irían dirigidos estos relatos, si sus hazañas serían escuchadas únicamente por los asiduos de la taberna, o si podrían ser recitadas junto a las gestas de condes como el de Chester en residencias nobles, tal como sugiere la cita de Langland.

La raíz de la actitud rebelde se ha querido encontrar en su relación con el mundo natural, con una naturaleza no roturada, ajena a la manipulación de los hombres. A pesar de que representó una de las fuentes de materia prima más importantes para la economía medieval, el bosque siempre se consideró irreductible, desconocido, peligroso, constituyendo por eso el lugar idóneo, el único refugio para quien quisiera desaparecer y no ser encontrado, para quien se ponía al margen de la ley de los hombres (Le Goff, 1986: 31). Para la mentalidad medieval seguía, pues, manteniendo su carácter amenazador e inquietante. Pero dado que no existía ámbito en el universo medieval que no estuviera poblado, debemos preguntarnos si existió un ser que aunara en sí todos esos valores, una encarnación del espíritu del bosque, una criatura tortuosa como la maleza, perenne y caduca, como la propia vegetación, un ser con vida propia, un hombre verde. Los antropólogos han

\footnotetext{
Thomas, el conde de Lancaster en la revuelta de los barones contra Eduardo II. Antes de esos registros de Wakefield sólo hay constancia en 1202 de un John Hood que vivía muy cerca de Barnsdale, zona donde se desarrollan los acontecimientos de la Geste. Sin embargo, según los datos de las crónicas escocesas, el rey en cuestión sería Eduardo I. Más tarde, en 1226 aparece en las sesiones del tribunal de York un fuera de la ley Robert Hood al que se le confiscan los bienes y que debe dinero a la iglesia de san Pedro de York. Después el nombre es tan común que se encuentra ya como apellido, dando cuenta de la celebridad del fugitivo.

2 Véase J. Gable (1939) y R. B. Dobson y J. Taylor (1976).

3 "I kan noght parfitly my Paternoster as the preest it syngeth,/ But I kan rymes of Robyn hood and Randolf Erl of Chestre" (Piers Plowman, B Text, passus V, 1. 395-5, ed. G. Kane and E. Talbot Donaldson, 1975: 331).

${ }^{4}$ Alrededor de 1530 el obispo Hugh Latimer visitó una parroquia en domingo y para su sorpresa encontró el edificio vacío porque todos los habitantes, incluido el cura, había dedicando el día a otro menester: actuar en el desfile de Robin Hood. Véase Hugh Latimer: Seven Sermons before Edward VI, ed. E. Arber, Londres, Murray, 1869.
}

Odisea, $n^{\circ} \quad 4,2003$ 
rastreado la existencia de este ser desde tiempos romanos en diversas partes de Europa: hojas de roble le crecen desde dentro y salen por su boca y orejas, rodeando toda su cabeza. Aunque en las primeras representaciones aparece simplemente la cabeza, poco a poco se le irá dotando de un cuerpo, igualmente cubierto de hojas. ${ }^{5}$

Que este ser representa originariamente el espíritu de la fertilidad, y que su ritual conlleva la lucha entre el verano y el invierno ha sido una de las tesis de la antropología, y esta postura ha inspirado a su vez aproximaciones mitologizantes de la figura de Robin Hood, dado que vestía de verde, sólo aparecía cuando llegaba el buen tiempo, en mayo o junio, y se llevaba mal con los representantes de la Iglesia. Resulta fácil que este ser, que sobrevive entre manantiales, cuevas, árboles y ciervos, que se desliza entre la hojarasca y la hiedra del bosque, llegue a concebirse como un trickster, un ser mágico cuya principal virtud está en su capacidad de transformación (Knight, 1994: 14). Nunca permanece igual ni en el mismo sitio, diversificándose como el propio paisaje boscoso y tendiendo trampas como la propia orografía. En este sentido, se resiste a toda autoridad convencional y encarna el propio espíritu del bosque, reducto de libertad. En tal paraje sobrevive sólo quien sabe adaptarse al medio y ceder a los caprichos de la naturaleza, mimetizándose en ella y olvidando las categorías primordiales con que nos solemos concebir.

Sin embargo, creemos que esta sugerente imagen del bosque y de su espíritu choca estrepitosamente con la evidencia histórica de que esa espesura boscosa, gran frontera para el mundo civilizado medieval, sí que cayó bajo la ley de los hombres, y precisamente por su carácter primigenio y sagrado. El bosque atesoraba las reservas de madera para la construcción y para el combustible diario, además de alimento. En Inglaterra muy pronto se reguló el uso del bosque y sus recursos mediante leyes que restringieron su aprovechamiento a los campesinos. ${ }^{6}$ Los bosques reales se convirtieron en cotos tras la conquista normanda, si bien el proceso de privatización tuvo su momento de apogeo a partir del siglo XIII, en que los parques privados proliferaron y se ampliaron en tamaño, hasta transformar el paisaje del siglo XIV.

Así el bosque se convierte en símbolo del privilegio natural de unos estamentos sobre otros, pues evoca los hechos de los ancestros, un tiempo primigenio en que se forjó la grandeza de reyes y nobles. En esta selva se formaliza el poder del hombre sobre el medio, y la violencia que allí se efectúa, la de la cacería, tiene casi un sentido ritual que sirve para delimitar el honor, la nobleza del hombre sobre el animal (Marvin, 1999: 225). Se transforma así en símbolo del dominio del hombre noble. Éste es el único que puede mostrar su honor en un entorno ya convertido en reserva sagrada, en santuario donde no se puede ingresar si se es ajeno al estamento. Quien traspasaba esos límites no sólo se percibía como hambriento y desobediente; era alguien que desafiaba ese honor esencial, el derecho al animal salvaje con el que se medían los bellatores, los defensores de esta sociedad, y por tanto desafiaba a la sociedad misma. Sería pues, un desafío lo que esta figura suponía; un desafío a los propios lazos parentelares que se esgrimían para protestar derechos de herencia sobre las reservas.

\footnotetext{
${ }^{5}$ Véanse los trabajos de B. S. Centerwall (1997), W. Anderson (1990), K. Basford (1978), y T. Husband (1980).

${ }^{6}$ Al respecto, véanse Ch. R. Young (1979), R. Grant (1991), y L. Cantor (1982).
} 
Según esta primera oposición social que se establece entre el hombre noble y el villano, podríamos aventurar que Robin Hood actuaba a favor de los campesinos privados de esa relación directa con el bosque. Según Hollister (1976: 134), en el siglo XII el campesino inglés medio era un siervo que vivía en comunidad, y dedicaba la mayor parte del tiempo a trabajar su predio con un arado pesado de ocho bueyes, dejando ciertos días para el cultivo de las tierras del señor. Molería su trigo en el molino de su señor y hornearía su pan en el horno señorial igualmente. ${ }^{8}$ En cuanto a la imagen que del campesino se proyectaba en esta época, era la esbozada desde la órbita superior de la nobleza; Le Goff (1969: 403) recuerda que la literatura y el arte medieval lo suelen ridiculizar comparándolo con una bestia y considerando que su gran pecado es la envidia. Es precisamente esta distorsión de la figura del labriego la que más tarde, en el siglo XIV, será contestada durante la revuelta de $1381 . .^{9}$ Los campesinos reclaman entonces, entre otras muchas medidas, que se generalice el disfrute de los bosques, y así, entre las peticiones de Wat Tyler encontramos lo siguiente: "[...] that all preserves of water, parks and woods should be made common to all: so that throughout the kingdom the poor as well as the rich should be free to take game in water, fish ponds, woods and forests, as well as to hunt hares in the fieldsand to do these and many other things without impediment."10

Se podría aventurar la posibilidad de que Robin Hood fuera un miembro de ese campesinado desasistido que hubiera rechazado la subordinación a los poderes locales que la estructura señorial iba reforzando. En este sentido, Eric Hobsbawm (1972) lo toma como modelo del bandolerismo social, fenómeno universal que se da en las sociedades en fase de evolución entre la organización tribal y familiar y la sociedad capitalista e industrial moderna. En este modelo, los implicados son ladrones lugareños que suelen regresar clandestinamente al pueblo del que proceden en temporada baja, y que reciben el apoyo de la población que los reconoce como amigos. Como en las sociedades campesinas resulta difícil abandonar el predio una vez se tiene familia y tierra que cuidar, los grupos idóneos para enrolarse en estas filas son los de jóvenes solteros de cualquier condición, a los que se pueden unir hombres armados y guardas de campo, o todo aquel que se resiste a la injusticia de forma individual. ${ }^{11}$

Sin embargo, la literatura parece rebatir la percepción del forajido como campesino renegado, como veremos. Desde el siglo XIII posiblemente, el género popular capaz de dar movimiento a este personaje fue la balada, de las que un gran número están dedicadas a

\footnotetext{
7 Véanse asimismo los enfoques clásicos de Robert Fossier (1985) y Georges Duby (1973).

${ }^{8}$ Pero si ésta podía ser la estampa tradicional, también es cierto que existía gran diversidad en el régimen de tenencia del campo inglés, como demuestran la obra de E. Miller y J. Hatcher (1978); véase asimismo J. A. Raftis (1964).

${ }^{9}$ Al respecto, véanse las obras clave Rodney Hilton de 1985 y 1988.

${ }^{10}$ Tomado del Chronicon Henrici Knighon (ed. J. R. Lumby, Roll Series, 1895) tal y como lo cita Marvin, op. cit., p. 230.

${ }^{11}$ Según Hobsbawm (ibid.), el ladrón noble se caracteriza por empezar como fugitivo por haber sido él mismo víctima de la injusticia; corrige los abusos; roba al rico para dar al pobre; no mata si no es en defensa propia o justa venganza; si sobrevive se reincorpora a la comunidad como un miembro honrado; es ayudado y admirado por su pueblo; su muerte se debe sólo a la traición; es invisible e invulnerable; y no es enemigo del rey sino de la nobleza, del clero y de otros agresores locales. Estos bandoleros, que son más activistas que ideólogos, forman parte del campesinado que intenta restaurar el orden natural existente antes de que surgiera la situación de injusticia, pero no suelen ser revolucionarios.
} 
Robin Hood -Child ha registrado 38-, ${ }^{12}$ algunas con música, otras simplemente recitadas. ${ }^{13}$ Aparte de ellas, existe otro texto que marca fuertemente la tradición del héroe, y que se llega a imprimir hasta siete veces en el siglo XVI. Esta obra, llamada La Geste of Robin Hood es la primera en reflejar con realismo el paisaje del norte de Inglaterra en que se desarrollan las peripecias, y de nombrar incluso al monarca que lo visita: Eduardo. En esta obra, todas las aventuras comentadas nos muestran a un Robin Hood de carne y hueso, un justiciero con el que cualquier oprimido podía identificarse frente al poder de los grandes señores y sus representantes. Además, el líder se gana el respeto de sus hombres por sus propias cualidades, fuerza, valor, astucia y determinación, y no por haber impuesto una estructura de poder en la banda. Podríamos considerarle uno más de los campesinos, opuesto a la cada vez mayor jerarquización que debilitaba las relaciones interpersonales entre tenentes y señores. ${ }^{14}$

\footnotetext{
${ }^{12}$ Todas las referencias a las baladas pertenecen a esta edición de Francis James Child: English and Scottish Ballads, 5 vols., Nueva York, Dover, 1965. Destaca entre sus fuentes el manuscrito llamado Percy Folio (descubierto por el obispo de Dromore, Irlanda, Thomas Percy 3/41782-18113/4 y publicado en 1765), que contiene algunas de las más antiguas baladas, tanto de la segunda mitad del siglo XIV como del XV.

${ }^{13}$ Ofrecemos la sinopsis de algunas de estas baladas: En Robin Hood and the Monk el héroe va solo a la iglesia, donde se encuentra con un monje que logra encerrarlo y entregarlo al sheriff, de forma que Little John, tras matar al monje, tendrá que hacerse pasar por él y llevar al rey unas cartas por las que Robin Hood alcanzará la libertad. Cuando el rey se entera del engaño, alaba la fidelidad de Little John para con su señor. En Robin Hood and the Potter se da el enfrentamiento entre el héroe y un desconocido que le vence, por lo que Robin Hood le pide que se una al grupo. Robin utiliza la ropa del otro para entrar en la ciudad y engañar al sheriff. Así, entra en Nottingham con la mercancía que venderá pronto y se presenta al torneo de tiro al arco que gana. Invitado a comer en casa del sheriff, lo embauca al decirle que en su carro lleva un arco que le dio Robin Hood y que puede llevarlo a su paradero. Así el sheriff lo sigue hasta el bosque, donde es desvalijado y devuelto a su casa a pie, mientras Robin envía a la esposa del sheriff un corcel. La balada termina con la burla de la mujer del sheriff y con Robin dando el dinero que ha ganado al alfarero, que se despide de él. Otra balada La travesía de Robin Hood Progress to Nottingham muestra a un Robin de 15 años que es acosado por 15 foresteros borrachos que compiten al tiro con arco y hacen una apuesta con el muchacho, que él ganará al acertar a un ciervo a gran distancia. Los foresteros se niegan a pagarle y Robin tiene que huir de ellos, sólo para regresar y matarlos a todos, refugiándose luego en el bosque. Aquí se presenta al forajido como un ser injustamente tratado, que se resiste a que se le burle y se le robe la pieza de caza y lo apostado. Esto haría de él un héroe para cualquiera de los oprimidos, y justificaría precisamente la muerte, sólo por traición, a manos de una priora y de un tal Red Roger, que perece en la lucha final.

${ }^{14}$ Comienza con la alegre banda esperando que se les acerque alguna víctima a la que obligar a cenar con ellos y a pagar la invitación. El elegido será Sir Richard at the Lee, un caballero que, al contrario que los monjes a los que suelen asaltar, les dice la verdad sobre la cantidad de dinero que lleva: muy poco, pues su hijo ha matado a un caballero y a su escudero; para librarlo de la justicia el padre ha tenido que hipotecar sus propiedades a la abadía de York por 400 libras, que debe reponer de inmediato. Robin Hood decide ayudarle, y así Little John bajo un nombre falso se presenta en la abadía como sirviente del caballero con el dinero que Robin le ha prestado y zanja la deuda, hospedándose en la casa del sheriff y participando en un concurso de tiro. Más tarde, y tras una pelea con el cocinero, lo convence para que abandone al sheriff y se una a la banda. El sheriff detiene a sir Richard, por lo que Robin irá a Nottingham a rescatarlo y acabar con el sheriff. El rey llega a la ciudad, se hace con las tierras del caballero, y tras seis meses se disfraza de abad y se interna en el bosque, donde encuentra a Robin, quedando impresionado por la lealtad que los hombres muestran hacia él. Al verlo tirar con arco, Robin lo identifica y le pide clemencia. Sir Richard recibirá sus tierras y Robin irá a vivir a la corte con el rey, de quien se ha hecho gran compañero. Pronto siente nostalgia y pide licencia para visitar la iglesia de María Magdalena. Una vez fuera, regresa al bosque, donde vivirá durante 22 años, hasta que la priora y Sir Roger logren matarlo, no sin que antes Robin pida a Little John que lo entierre allí donde caiga la última flecha que lanza.
} 
Sin embargo, apenas encontramos campesinos siervos en estos textos. De Robin Hood sólo en las baladas tardías se dice que funda casas de acogida para necesitados, si bien es cierto que la Geste concluye pidiendo por su alma: "Cryst have mercy on his soule,/ that dyed on the rode!/ For he was a good outlawe,/ and dyde pore men moch god" (p. 78, estr. 456). Así pues, si las baladas no hablan de y para los campesinos, entonces ¿para quién? La Geste se abre con las siguiente llamada: "Lythe and listin, gentilmen/ that be of frebore blode,/ I shall you tel of a gode yeman,/ his name was Robyn Hode” (p. 56, estr. 1). Más tarde, Robin advierte a sus hombres de no dañar a campesino ni a yeoman:

'Thereof no force,' than syade Robyn;/ 'We shall do well inowe;/ but loke ye do no husbonde harme/ that tilleth with his ploughe./ No more ye shall no gode yeman/ that walketh by grene-wode shawe;/ ne no knyght ne no squyer/ that wol be a gode felawe./ These bisshoppes and these archebishoppes,/ ye shall them bete and bynde; the hye sheriff of Notyingham,/ hym holde ye in your mynde." (p. 57, estr.13-15).

Ante la evidencia literaria, la crítica ha tenido que ser más precisa en la descripción del grupo social para el que pudieron ser compuestas las mismas, razón ésta que podría igualmente hablarnos sobre el origen del héroe. Este vocablo, "yeoman" se refiere en los siglos XVI y XVII al agricultor rico que posee su propia tierra y emplea a otros para trabajarlas, situado por debajo del caballero y del escudero. Pero dos siglos antes, el significado de la palabra no era el mismo. Encontramos dos yeomen de The Canterbury Tales, uno sirviendo al escudero y al caballero y otro al canónico. El primero a su vez es un forestero, y su atuendo recuerda ciertamente al de Robin Hood. ${ }^{15}$

A partir de los estudios de Young (1969) ${ }^{16}$ se ha venido a considerar al yeoman un agricultor dueño de su propio alodio, un campesino libre, ni tan rico como el del siglo XVI ni un mero sirviente como el de la época de Chaucer. Si esto es así, el descontento que se expresa no es el del campesinado oprimido sino el de estos pequeños propietarios que a finales del siglo XIV habían sido perjudicados por la subida de los sueldos de los aparceros como resultado de la demanda de mano de obra que hubo tras la Peste de 1348. Richard

\footnotetext{
15 "And he was clad in cote and hood of grene./ A sheef of pecok arwes, bright and kene,/ under his belt he bar ful thriftily/ (Wel koude he dresse his takel yemanly;/ his arwes drouped noght with fetheres lowe),/ and in his hand he baar a myghty bowe./ A not heed hadde he, with a broun visage./ Of wodecraft wel koude he al the usage./ Upon his arm he baar a gay bracer,/ and by his syde a swerd and a bokeler,/ and on that oother syde a gay daggere/ harneised wel and sharp as point of spere;/ a Cristopher on his brest of silver sheene./ An horn he bar, the bawdryk was of grene;/ a forster was he, soothly, as I gesse." (I A, 103117, en The Riverside Chaucer, 1888: 25). Jill Mann (1973: 172) recuerda que este personaje no es conocido en la sátira de los estamentos hasta que aparece reflejado en esta obra; más tarde, en el siglo XVI sí que aparece en un poema sobre el cuerpo estatal. Véase al respecto "The descrying of mannes membres", en J. Kail, ed. (1904: 65).

${ }^{16}$ N. Para el siglo XV, la descripción que da A. J. Pollard (2000: 189) es la siguiente: “ [...] by the fifteenth century it had become a description of the social status of a countryman who held some sixty acres of land, freehold or customary, employing one or two farm hands, and enjoying a sufficient income to make him and his family comfortable and independent. They were sometimes still called franklins. Yeomen were less than gentlemen: they worked. They were more than husbandmen, because they were more prosperous. Yet they rubbed shoulders with husbandmen, artisans and traders in small town and country, many of whom combined small-scale husbandry with business and who, under the terms of the Statute of Additions, could with commendable flexibility be styled yeoman, alias chaplain, alias mercer."
}

Odisea, $n^{\circ} 4,2003$ 
Tardif (1983), por otro lado, observa que las baladas ni siquiera están interesadas por el campo, apuntando siempre a una zona de libertad que existe cerca de la ciudad. El término "yeoman" adquiriría entonces un sentido cercano al de "tratante", por lo que las baladas mostrarían el despertar de la conciencia de la nueva clase del artesanado urbano que no tenía propiedades.

De hecho, las baladas no contienen agricultores ni propietarios, están alejadas de cualquier situación reconocible, y no remiten a revueltas de ningún tipo. En ellas, figuras como el alfarero, el cocinero o el fraile son tentadas por la generosidad y la libertad de los forajidos, que suplen las carencias de una naciente economía mercantil y su sistema de salarios, que podía parecer insuficiente y sospechoso al artesanado. Así, las baladas mostrarían la oposición de estos héroes antiguos, generosos y aventureros al exceso de burocratización, legalismo y mercantilismo representado por la ciudad, y que iría en aumento a lo largo de los siglos XIV y XV. Esta adaptación del personaje, fuera cual fuera su origen, a las circunstancias de estos últimos siglos nos permiten verlo bajo una nueva óptica, pues su oposición a las estructuras señoriales no surgiría del rechazo de la opresión de los campesinos tanto como de una rivalidad entre este grupo social en alza y el ya establecido, la nobleza. Se trata éste de un momento en que incluso la práctica del feudalismo ha perdido sus rasgos primigenios; en el que el espíritu de servicio y protección personales que regulaban unas instituciones vasalláticas se ha perdido.

De nuevo la literatura viene a corroborar esta erosión de los principios del feudalismo: en la Geste destacan algunas prácticas tardomedievales, como el detalle de que a Robin le extrañe la pobreza de sir Richard at the Lee, y se pregunte si aquél se habría visto obligado a hacerse caballero. También encontramos ejemplos de corrupción económica, cuando el sheriff intenta retener a Little John, creyéndolo Reynald Grenelef, por veinte marcos al año, o cuando el oidor del rey es sobornado por el abad. Todas estas mañas proliferan cuando las relaciones permanentes de tenencia feudal se descomponen en asociaciones de lo que se ha dado en llamar "feudalismo bastardo"17 en Inglaterra.

Este fenómeno había tenido precedentes desde la conquista normanda, pues desde el propio siglo XI algunos arrendatarios habían intentado librarse de su obligación de prestar servicio militar a su señor a cambio del pago de una tasa. Con el tiempo, los reyes utilizaron esa tasa para pagar de forma regular a huestes mercenarias, poniendo así en evidencia la fragilidad del sistema de tenencia. En el siglo XIII Eduardo I prohibió el proceso de subenfeudamiento y la vieja práctica de prestar servicio militar como compensación por recibir la tenencia de tierras fue muriendo a medida que los ejércitos se fueron modernizando. Mientras que aumentó la importancia de la infantería que tiraba con arco, decreció el poder de la caballería, y el rey, mediante el Estatuto de Winchester de 1285 concedió el derecho a los notables locales de formar sus propias mesnadas según determinadas obligaciones. Además, el rey estableció contratos de por vida con señores principales, que debían proveer contingentes de mercenarios para el ejército cuando fuera necesario a cambio de estipendios regulares. Este sistema se amplió a su vez a la relación existente entre el señor y sus tropas, cuyos líderes firmaban estas mismas cartas con sus bandas de hombres. Como el contrato solía vincular a los guerreros a sus señores de por vida, este nuevo sistema vino a sustituir la relación feudal, dando lugar en el siglo XIV a una jerarquía social ligada por el dinero más que por la tenencia de la tierra. 
Esto nos lleva a cuestionarnos cómo podría afectar esta situación económica y social a la supervivencia de las bandas de forajidos. Normalmente en este bandolerismo se vive al día, tras ponerse en circulación el dinero que se roba o al venderse el botín. Repartirlo con los necesitados es menos frecuente, aunque las familias de los prófugos sí se suelen ver beneficiadas. Sólo en ocasiones puede darse el caso de que estos marginales se enriquezcan, al relacionarse con intermediarios que los ponen en contacto con los sectores más dinámicos de la economía local. Por otro lado, el exceso de control que ejercía la cada vez mejor organizada burocracia inglesa sobre los súbditos ingleses en los últimos siglos hizo, según Hilton (1958: 37), que la delincuencia se transformara lentamente en un suceso cada vez más común:

By the thirteenth century outlawry was becoming less serious. An accused person who neglected to appear at four successive county courts for trial was automatically outlawed. Outlawry was becoming a sanction to compel attendance at court. But though it might no longer involve the lawful killing of the outlaw (except for resisting capture) it did involve the forfeiture of land and goods. Many a man who was not confident that law was the same as justice might prefer outlawry. ${ }^{18}$

Estas drásticas medidas harían proliferar un bandidaje circunstancial, y ampliaría muchísimo la cantidad de prófugos. Holt ${ }^{19}$ cree que los yeomen, sirvientes sin familia ni propiedades o campesinos libres en apuros, serían los elementos idóneos para entrar a formar parte de esa nueva caballería mercenaria de los siglos XIII y XIV, o bien para dedicarse a tener sus propias bandas de forajidos al margen de la ley. Un ejemplo de estos tipos serían el caballero sir Richard y el propio Robin. Se trataría, por tanto, de bandas con cierto poder y reconocimiento social, concedido incluso por los propios nobles. Por otro lado, recordemos que esas bandas no sólo suponen una fuerza comercial sino también armada y que, por tanto, pueden llegar a un entendimiento con el poder local que depende de una red de afiliaciones y protección. Cuando esta red falla, por debilidad o desinterés de las autoridades superiores, los bandidos pueden suponer una reserva local de hombres armados para cualquier emergencia. De ahí que la estructura de la política rural se avenga a fomentar este bandidaje, que acaba siendo integrado allí donde el aparato central no es sólido, principalmente en zonas fronterizas, o en momentos en las que tiende a resurgir la anarquía feudal. ${ }^{20}$

Si estos forajidos son idealizados por el tercer estamento, ello se debe no sólo a una supuesta disposición levantisca en el campesinado, sino a una condición estructural de esta sociedad, por la cual el bandido es requerido como figura llamada a preservar, por oposición, la pureza de las formas y el proceder de la nobleza, salvaguardando la pervivencia de ese grupo. De ahí que el forajido sólo se enfrente a los representantes del poder local y

\footnotetext{
${ }^{17}$ Sobre este concepto, que tras debatirse durante más de un siglo, se considera inadecuado para expresar la erosión sufrida por el feudalismo clásico, véase la obra de M. Hicks (1995).

${ }^{18}$ En cuanto a la evolución de la criminalidad en Inglaterra, véanse J. Bellamy (1973) y más recientemente Barbara Hanawalt, ed. (1992).

${ }^{19}$ Op. cit.

${ }^{20}$ En cuanto a los problemas que representaba la frontera con Escocia para los territorios del norte, véase G. Barrow (1989).
}

Odisea, $n^{\circ} 4,2003$ 
eclesiástico corrupto, y no a las propias instituciones, en las que se encuentra plenamente integrado y acomodado. Si estos delincuentes cargan, como todo chivo expiatorio, con las culpas de una sociedad que tiene sus fracturas y fallas, en compensación, su figura es enaltecida y la reinserción del delincuente sólo se produce, paradójicamente, mediante su persistencia en tal condición. El forajido es así, de alguna manera, institucionalizado. El reflejo que esto tiene en la literatura es la casi camaradería que llega a existir entre Robin y el monarca, el cual no se siente nunca amenazado por un ser que representa una disidencia bien encauzada y estructurada, la cual da cabida a individuos que de otro modo quedarían fuera del esquema social y mental del medievo. Frente a las simpatías que Robin despierta en los monarcas con los que comparte andadura literaria, resulta tristemente irónica la contundente respuesta que los campesinos alzados en 1381 recibieron de Ricardo II.

Robin nunca avanza hacia la capital del reino; de hecho, apenas sale del espacio vital y simbólico que se le ha adjudicado: el bosque. Sólo reacciona contra los representantes reales que ponen en peligro la armoniosa relación entre monarca y súbditos. El sheriff era el agente financiero local de la corona y maestro en el arte de la extorsión, estando al mando de una red de espías y funcionarios que ponían en movimiento todo un proceso que culminaba en el juicio. ${ }^{21}$ Además era el oficial encargado de recibir las quejas de los terratenientes agraviados cuando los arrendatarios se demoraban en pagar o en prestar servicios. Este puesto fue ocupado por importantes prohombres locales que participaron en la administración real del campo, recaudando los impuestos y acompañando a los oidores reales en sus viajes. Así pues, cualquier desmán que sufrieran campesinos libres o no, o villanos de cualquier condición, podía achacarse a la ambición y deslealtad del sheriff, si bien en ocasiones sólo cumplían órdenes de la cancillería. ${ }^{22}$ De nuevo, vemos como los forajido se oponen no sólo a los que desposeen a los pobres, sino a cualquier elemento que amenace la frágil armonía que existe entre esos diversos intereses locales y las instancias superiores. En este sentido, en las baladas son siempre los abades acaudalados y estos agentes locales los que se presentan como avariciosos, sugiriéndose con ello un punto de felonía para con la corona. Así, la popularidad de Robin se confirma al ser blanco de las iras de una de las figuras más desprestigiadas del panorama político local, el sheriff, y al elegir como víctimas a los poderosos abades, figuras doblemente odiadas: al célebre amor de los clérigos por los bienes terrenales se venía a sumar la oposición entre el poder laico y el eclesiástico que en Inglaterra se habían explicitado desde tiempos de Enrique II y de su hijo Juan, de los cuales el pueblo se hizo eco. ${ }^{23}$

\footnotetext{
${ }_{21}$ Otro motivo de impopularidad es que está encargado, en época de Eduardo I, de desposeer de sus franquicias a quienes no puedan demostrar que éstas han sido concedidas por reyes anteriores a Ricardo I o por privilegio real. Sobre esta figura, véase W. A. Morris (1927).

${ }^{22}$ Sobre esta relación a finales del siglo XIII, dice Hilton (1988: 33): "Las cartas patentes y cerradas son especialmente valiosas porque esas cartas salidas de la cancillería, ordenando a los sheriffs o a otros oficiales reales emprender acciones en favor de los propietarios contra los siervos rebeldes, frecuentemente proporcionan todos los detalles de los casos que habían de tratar los sheriffs o los agentes". ${ }^{23}$ Según Holt (op. cit., p. 152) en el invierno de 1231-32 hubo manifestaciones contra el clero extranjero que gozaba de beneficios en Inglaterra, y dos mensajeros papales fueron atacados por una banda cuyo líder era el caballero Robert de Thwing, bajo el seudónimo de William Wither. Al igual que los hombres de Robin, éstos usaban arco y flecha, ataban a sus víctimas y pedían rescate por ellas o las desvalijaban directamente.
} 
Llegados aquí, sabemos que de forma natural, debido a su fama, el héroe se asoció a las reivindicaciones de los más diversos grupos; ${ }^{24}$ pero no estamos tan seguros sobre qué cauces de difusión siguió la leyenda. Para la crítica tradicional, las baladas son un género popular, nacido de una artesanía literaria que da este formato al relato de los hechos acontecidos y transmitidos oralmente. ${ }^{2} 5$ Los contenidos cubren las aspiraciones y los tipos de los que las clases populares disponen y con los que se identifican. Sin embargo, y en relación con la evolución que hemos observado del propio héroe, las baladas podrían suponer igualmente una derivación de otros géneros producidos en círculos cultos. Algunas de ellas serían escuchadas en mansiones provinciales donde el auditorio estaría compuesto por baja nobleza o por yeomen bien situados. Estas familias, con todo su séquito de poetas y sirvientes se desplazarían, llevando con ellas sus relatos, que se extenderían así desde su lugar de origen en el norte hacia el resto de Inglaterra. Precisamente en el norte del país se detecta una potente fuerza de yeomen entre 1348 y el siglo XV, existiendo al menos veinte grandes mansiones que mantenían un cuerpo regular de juglares, fabuladores y autores, que a su vez viajaban para entretener a las abadías, o actuaban en mercados, fiestas religiosas y posadas. ${ }^{26}$ Así pues, tanto señores como siervos pudieron finalmente compartir las hazañas de Robin Hood, un personaje que de las posadas y las plazas habría acabado "asaltando" las mansiones de aquellos magnates en pleno ascenso, cuya situación no se veía amenazada por el hombre verde, quien después de todo, provenía de sus mismas filas.

Uno de los efectos de este ascenso de la balada sería el del contacto con romances $\mathrm{u}$ otros géneros que acabarían dando buena cuenta del talante positivo que esta sociedad atribuía al forajido. Esto nos lleva a cuestionar desde qué instancias se pudo proponer un Robin Hood noble. La balada no requiere de la nobleza del forajido para difundirse con éxito. Sin embargo, existe otro género que sí opera desde estas premisas, y así serán precisamente las crónicas las primeras interesadas en transformar al ladrón en señor y en difundir ese nuevo modelo. Sin embargo, resulta difícil averiguar el grado de contacto de estos cronistas con las baladas o con romances de motivos similares que circularan por el país. ${ }^{27}$ A pesar de su vocación histórica, estas crónicas comparten con otros relatos legendarios los motivos del retiro al bosque, la reconciliación con el rey, la habilidad en las armas y en el arte del disfraz, o el engaño al sheriff, por lo que podríamos incluso aventurar un contacto con baladas que registran leyendas coetáneas las de Robin, dedicadas a glosar la vida de otros yeomen cazadores furtivos, como William de Cloudesley, Adam Bell o Clim of the Clough, ${ }^{28}$ con nuevos elementos en común, como el torneo de tiro al arco, o el

\footnotetext{
${ }^{24}$ De nuevo, es Holt (op. cit.) quien recoge que en Norfolk en 1441 un grupo de trabajadores y yeomen bloquearon la carretera contando que eran hombres de Robin Hood e imitando un desfile procesional. En 1497 Roger Marshall de Westbury aparece defendiéndose en la Star Chamber de la acusación de haberse hecho pasar por Robin Hood para liderar una revuelta en Willenham, y en Escocia un grupo de aprendices y artesanos se alzaron al grito de Robin Hood en Edimburgo en 1561.

${ }^{25}$ Véase el estudio sobre la balada de C. C. Fowler (1968),o el clásico capítulo sobre la poesía narrativa popular y la balada en E. K. Chambers (1945).

${ }^{26}$ Véase especialmente P. R. Coss (1985) y J. C. Holt (1960).

27 Recordemos la afirmación de Pearsall (1965: 91-92): "The audience of Middle English romances is primarily a lower or lower-middle class audience, a class of social aspirants who wish to be entertained with what they consider to be the same fare, but in English, as their social betters".

${ }^{28}$ El estudio más completo sobre personajes fugitivos de distinto signo, desde rebeldes como Wallace hasta forajidos como Robin Hood, sigue siendo el de M. Keen (2000).
}

Odisea, $n^{\circ} 4,2003$ 
rescate de los que están en el cadalso, o la intercesión de la reina. Dado el grado de difusión de estas leyendas, se podría argüir que las baladas y los romances tuvieron el mismo tipo de auditorio en el momento en que esa baja nobleza de procedencia campesina y popular vio con buenos ojos el ascenso de su antiguo héroe. Posiblemente, en ese ambiente las baladas no fueran ya cantadas, sino recitadas. ${ }^{29}$

Curiosamente, las tres primeras crónicas que incluyen a Robin son de autores escoceses, cercanos a la zona de su posible origen. La de Andrew Wynton, The Orygynale Chronicle (1420) lo coloca en la época de Eduardo I, vinculándolo a los sobrevivientes escoceses de la batalla de Berwick de 1296, que se refugiaron en los bosques. E1 Scotichronicon de Walter Bower (1441) se mantiene en la tradición antiinglesa pero lo presenta como personaje cruel, añadiendo datos tan significativos como que habitaba en Barnsdale, y que pudo haber sido uno de los disidentes que se puso del lado de Simón de Montfort en su rebelión contra Enrique III, permaneciendo en el bosque tras la muerte de aquél en $1265 .{ }^{30}$ La crónica de John Major, Historia Majoris Britannia (1521), ignora la mención que se hace en la Geste a la llegada de "Edward our comely king" y decide librar al héroe del problemático periodo de disensión entre la nobleza y la monarquía y de las implicaciones proescocesas del reinado de Eduardo I. Consecuentemente, lo aleja hacia la época de Ricardo I y su hermano menor, el príncipe Juan, y Robin se transforma así en adalid del monarca cruzado frente al más impopular e incapaz de los reyes ingleses, Juan sin Tierra. ${ }^{31}$

En 1569 Grafton escribe en inglés su Chronicle at Large, siguiendo a Major y añadiendo que la gente ya cantaba en toda Inglaterra las hazañas de Robin Hood, al que describe como un impecable conde de buen corazón y mejor puntería, que por traición se vio desposeído y se dedicó a la malandanza. Esta versión aristocratizante del héroe revierte en la balada y se confirma y populariza sobre todo mediante el teatro profesional de fines del XVI, sediento de nuevos temas, ${ }^{32}$ el cual viene a suplantar en cuanto al estatus del

\footnotetext{
${ }^{29}$ De hecho, Fowler (op. cit., pp.72-80) señala la técnica, común en la Geste y los romances, de la repetición de incidentes, lo que podría delatar este contagio.

${ }^{30}$ Maurice Keen registra cómo entre 1266 y 1272 Nottinghamshire y algunas zonas de Derby aparecen como el centro de actividades de una importante guerrilla liderada por un tal Roger Goldberd, fugitivo tras la derrota de Simón de Montfort contra Enrique III, a cuya causa se había unido (1264-5). Goldberg se había dedicado a atacar la abadía de Garendon y a amenazar Nottingham. Durante la persecución, encontró la protección de un prominente caballero local, Richard Foliot, que también había tomado parte en la revuelta de los barones. Los historiadores han querido ver en estos sucesos el origen de la trama de la Geste de Robin Hood, relacionando a este Richard Foliot, que debió luego rendir cuentas al rey, que lo perdonó, con el sir Richard de la Geste.

${ }^{31}$ Puede que Major estuviera tomando como modelo la figura histórica de Fulk Fitz Warren, un barón de los pantanos galeses nacido en 1170 que, tras ser desposeído de sus tierras, se levantó contra el rey Juan y en 1203 recobró sus dominios, del cual existe un poema en francés normando del que hubo una versión inglesa en el siglo XIII. De hecho, podemos decir que existía una tradición de romances que trataban de estos nobles venidos a menos. Uno de esos relatos verídicos fue el de Hereward de Wake, considerado el líder de la resistencia anglosajona contra los normandos. También fue famosa la figura de Eustace the Monk, de una casa noble del condado de Boulogne, y que salío del monasterio en el que había ingresado para vengar a su padre, convirtiéndose en soldado de fortuna que sirvió tanto a Juan en Inglaterra como al rey Felipe en Francia, del que se compuso un romance en francés en 1223,"Wistasse li Moine".

${ }^{32}$ Entre muchas otras, destaca la tragedia de Anthony Munday (1598-99), The Downfall and the Death of Robin Hood, Earl of Huntingdon que definitivamente presenta como malvados maquiavélicos al príncipe
} 
héroe, a los festivales populares que mantenían la figura villana de Robin. ${ }^{33}$

Siempre a favor de la monarquía, en el siglo XVI Robin Hood viene a encarnar la convivencia en la Inglaterra tudor de la aristocracia y las emergentes clases medias con aspiraciones a transformarse en nobleza. ${ }^{34}$ En este joven siglo XVI, el forajido que mora en el bosque de Sherwood, pero que puede aparecer igualmente en cualquier punto de la geografía nacional, tiene ya la legitimidad que le permite habitar en el bosque, pues es noble. En el momento en que el héroe comienza su claro ascenso social a partir de la crónica, en una época en que la delincuencia y la mendicidad se generalizan, y en que a esta cultura del hambre corresponde otra de la ostentación, ${ }^{35}$ Robin Hood se adapta a su nueva identidad de noble y adquiere como rasgo identificador una de las virtudes más prestigiosas en este momento: la caridad. Es desde estas alturas, plenamente reconocido como modelo del buen bandido -cuya generosa naturaleza corresponde a su noble sangre-, como el fugitivo se adaptará al nuevo paisaje social del incipiente capitalismo inglés. Se adapta, pues, a un nuevo momento histórico, sin alterar su popularidad. Pero de nuevo, este dar a los pobres no es sino la nueva cara que adopta la institucionalización de la pobreza: el benefactor suplanta al señor, toda vez que las relaciones interpersonales contraídas mediante lazos feudales se pierden. Como recuerda Riera i Melis (1996: 48):

La mendicidad, considerada como oficio, generará en la etapa final de la Edad Media, unas técnicas profesionales, unos usos específicos y unos reflejos corporativos. Ningún razonamiento moral apuntará a la supresión de la pobreza; su desaparición no es deseable, puesto que los desvalidos establecen una mediación indispensable entre los hombres normales, socialmente integrados, y Dios.

Juan y a su madre Leonor de Aquitania, que hacen caer en desgracia al noble Robin. Una de las versiones más famosas la ofrece Martin Parker en 1632, en el relato A True Tale of Robin Hood, donde definitivamente lo presenta como el conde de Huntingdon, un caritativo conde y arquero consumado que se arruina por generoso, siendo el agente de su ruina el abad de Sta. María. Su principal enemigo será la Iglesia católica, cuya falta de caridad y sinceridad contrasta con la del héroe, representante ahora del espíritu protestante y moderno.

${ }^{33}$ Irónicamente, la figura de la futura Lady Marian procede de estos festivales populares. Si bien se ignora en qué momento se unieron ambas figuras como rey y reina del bosque, tenemos constancia de una pequeña pieza pastoral culta de Adam de la Halle, Le Jeu de Robin et Marion (1280), que se representaba en Pentecostés en Angers, en la cual Marian o "Murrian" es una pastora y él su rústico amante, que ve amenazado su idilio por un caballero. John Gower introdujo esta tradición culta en Inglaterra en el siglo XIV, pero posiblemente ya hubiera entrado por otras vías, topándose con las canciones heroicas del prófugo rebelde que actuaba siempre en verano. La leyenda de Robin y Marian como Señor y Señora de Mayo acabó fusionándose con la procesión de los mummers de invierno en época isabelina, de forma que en las procesiones desfilaban como defensor del pueblo contra o un líder turco o un barón opresor bien un san Jorge, bien un Robin Hood. Éste intimidaba y obligaba a los entusiasmados asistentes a ser generosos en la colecta final, tras haberles animado antes a rebelarse contra la autoridad. Véanse al respecto E. K. Chambers (1996: 171 \& ff) y G. Wickham (1987: 141 \& ff).

${ }^{34}$ En la crónica de Edward Hall (1548) se nos dice que en el carnaval real de 1510 Enrique VIII y otros nobles entraron en los aposentos de la reina ataviados como Robin Hood y tras bailar con ella se retiraron. Más tarde, en 1515, mientras la pareja real paseaba por las colinas de Shooters los acosaron doscientos hombres de verde que los invitaron a entrar a la espesura donde les esperaban exquisitas viandas y un torneo de tiro con arco.

${ }^{35}$ A. Kinney (1973).

Odisea, $n^{\circ} \quad 4,2003$ 
En un momento en que la pobreza no sólo generó mendicidad sino también inconformismo y exigencia de justicia social, la opción de este Robin Hood fue la de seguir representando al bandido que piensa en los pobres “desde arriba.". Por otro lado, se trata de un Robin Hood mucho más consciente de su propia situación de noble desposeído, sabedor de que se encuentra en un mundo en el que los privilegiados pueden también llegar a pasar hambre -como bien demuestran nuestros hidalgos-, ya que la rueda de la fortuna gira ahora a mucha más velocidad y atrapa en su carrera al ladrón más ágil.

\section{OBRAS CITADAS}

Anderson, W. 1990. Green Man. Londres: Harper Collins.

BArrow, G. 1989. "Frontier and Settlement: Which Influenced Which? England and Scotland, 1100-1300”. Medieval Frontier Societies. Ed. R. BARLETT y A. Mackay. Oxford: Clarendon. 2-21.

BASFORD, K.1978. The Green Man. Ipswich: D. S. Brewer.

Bellamy, J.1973. Crime and Public Order in England in the Later Middle Ages. Londres: Routledge.

Cantor, L.1982. "Forests, Chases, Parks and Warrens". The English Medieval Landscape. Ed. L. Cantor. Philadelphia: University of Pennsylvania Press. 56-85.

Centerwall, B. S.1997. “The Name of the Green Man”. Folklore 108: 25-33.

Chambers, E. K.1945. English Literature at the Close of the Middle Ages. Oxford: Clarendon.

Chaucer, G. 1988. The Riverside Chaucer. Ed. L. Benson. Oxford: Oxford, Nueva York y Toronto.

Coss, P. R. 1985. “Aspects of Cultural Diffusion in Medieval England: The Early Romances, Local Society and Robin Hood”. Past and Present 108: 35-79.

Davis, N., ed. 1971. Paston Letters and Papers. Oxford: Clarendon.

Dobson, R. B. y J. TAylor 1973. Rymes of Robyn Hood. Londres: W. \& J. Mackay.

DuBY, G.1973. Economía rural y vida campesina en el occidente medieval. Barcelona: Península.

Fossier, R.1985. Historia del campesinado en el occidente medieval. Barcelona: Crítica.

Fowler, C. C.1968. A Literary History of Popular Ballad. Durham, North Carolina: Duke University Press.

Gable, J.1939. Bibliography of Robin Hood. Nebraska: University of Nebraska Press.

Grant, R.1991. The Royal Forests of England. Phoenix Mill: Alan Sutton.

Hanawalt, B. ed. 1992. Chaucer's England: Literature in Historical Context. Minneapolis: University of Minnesota Press. 
Hicks, M.1995. Bastard Feudalism. Londres: Longman.

Hilton, R. H.1958. “The Origins of Robin Hood”. Past and Present 14: 30-44.

— 1985. Siervos liberados: Los movimientos campesinos medievales y el levantamiento de 1381. Madrid: Siglo XXI.

— 1988. Conflicto de clases y crisis del feudalismo. Barcelona: Crítica.

Hobsbawm, E. J. 1972. Bandits. Harmondsworth: Penguin.

Hollister, C. W.1976. This Realm of England, 55 b.c. to 1399. Lexington, Toronto y Londres: D. C. Heath.

Holt, J. C.1960. “The Origin of the Ballads of Robin Hood”. Past and Present 18: 89110.

— 1989. Robin Hood. Londres: Thames \& Hudson.

Husband, T.1980. The Wild Man: Medieval Myth and Symbolism. New York: The Metropolitan Museum of Art.

KaIL, J. ed. 1904. Twenty-Six Political and Other Poems. Londres: EETS o.s. 124.

KeEn, M. 2000. The Outlaws of Medieval England. Londres y Nueva York: Routledge.

KInNEY, A.1973. Rogues, Vagabonds and Sturdy Beggars. Massachusetts: Imprint Society.

Knight, S.1994. Robin Hood: A Complete Guide of the English Outlaw. Oxford y Cambridge, MA: Blackwell.

Le Goff, J. 1969. La civilización del occidente medieval. Barcelona: Juventud.

— 1986. Lo maravilloso y lo cotidiano en el occidente medieval. Barcelona: Gedisa.

Mann, J. 1973. Chaucer and Medieval Estates Satire. Cambridge: Cambridge University Press.

Marvin, W. P. 1999. "Slaughter and Romance: Hunting Reserves in Late Medieval England". Medieval Crime and Social Control. Ed. B. Hanawalt y D. Wallace. Minneapolis y Londres: University of Minesota Press. 224-252.

Miller, E. y J. HATCher 1978. Medieval England: Rural Society and Economic Change, 1086-1348. Burnt Mill: Longman.

Morris, W. A. 1927. The Medieval English Sheriff to 1300. Manchester: Publications of the University of Manchester.

PeARSAll, D. 1965. “The Development of Middle English Romance”. Medieval Studies 27: 91-92.

Pollard, A. J. 2000. Late Medieval England, 1399-1509. Edinburgh Gate: Longman.

Raftis, J. A. 1964. Tenure and Mobility: Studies in the Social History of the Medieval English Village. Toronto: Pontifical Institute of Mediaeval Studies. 
Riera i Melis, A. 1996. "Pobreza y alimentación en el Medieterráneo Noroccidental en la Baja Edad Media". La Mediterrania, àrea de convergència de sistemes alimentaris (segles V-XVIII). Ed. María BARCELó CReSPí. Palma: Jornades d'Estudis Histórics Locals, Govern Balear. 39-72.

Tardif, R. 1983. "The 'Mistery' of Robin Hood: A New Social Context for the Texts". Words and Worlds: Studies in the Social Role of Verbal Culture. Ed. S. KNIGHT y S. N. MuknerJeE. Sydney: Sydney Association for Studies in Society and Culture. 130-145.

Young, C. R.1979. The Royal Forests of Medieval England. Leicester: Leicester University Press.

Young, N. D. 1969. The Country Gentry in the Fourteenth Century. Oxford: Clarendon. 